\title{
Influence of antiphospholipid antibody positivity on glomerular filtration rate markers in a group of systemic sclerosis patients - a 24-month observation
}

\author{
EWA WIELOSZ ${ }^{1}$, MARIA MAJDAN ${ }^{l}$, ARKADIUSZ KOSZARNY ${ }^{l}$, MAGDALENA DRYGLEWSKA ${ }^{l}$, \\ JACEK TABARKIEWICZ ${ }^{2}$
}

${ }^{1}$ Department of Rheumatology and Connective Tissue Diseases, Medical University of Lublin, Lublin, Poland

${ }^{2}$ Centre for Innovative Research in Medical and Natural Sciences, Medical Faculty of University of Rzeszow, Rzeszow, Poland

\begin{abstract}
Aim of the study: The aim of the study was the assessment of changes in the glomerular filtration rate (GFR) during long-term observation in a group of systemic sclerosis (SSc) patients with and without chronic antiphospholipid (aPL) antibody positivity.

Material and methods: The observation comprised 50 patients -23 with diffuse cutaneous SSc$d c S S c$ and 27 limited cutaneous SSc-lcSSc. After 24 months we assessed 27 patients (9 died, 14 lost follow up); 24 patients (88\%) were treated chronically with angiotensin-converting-enzyme inhibitors (ACEIs). Patients were investigated for the presence of aPL: to cardiolipin and to $\beta 2$ glycoprotein I in $I g M$ and IgG classes. Serum levels of creatinine $(S-C r)$, cystatin $C$ and creatinine clearance values were determined in all patients. According to the presence of a significant level of at least one of aPL antibodies, pts were divided into groups: group I aPL positive: 14 patients, group II aPL negative - 13 patients.

Results: We did not find significant differences in $\mathrm{S}-\mathrm{Cr}$, cystatin $\mathrm{C}$ levels and creatinine clearance before and after 24 months of observation between both groups. In follow up observations, the presence of anti-centromere antibodies was significantly more frequent in the aPL positive, as compared to the aPL negative group $(p=0.01)$. In follow up observations, the level of anticardiolipin antibodies in IgG class was significantly higher in dcSSc compared to lcSSc patients $(p=0.02)$.

Conclusions: In long-term observation chronic positivity for aPL antibodies does not significantly decrease the GFR in patients with SSc treated with ACEIs.
\end{abstract}

Key words: systemic sclerosis, antiphospholipid antibodies, renal function assessment.

(Centr Eur Immunol 2017; 42 (2): 161-166)

\section{Introduction}

Systemic sclerosis (SSc) is a heterogeneous, systemic disease characterized by microvascular damage, disorders of the immune system and multiple organ fibrosis. The dominant component of SSc pathophysiology is vascular damage, which can occur early in the course of the disease and affect different internal organs mainly the lung, heart and kidney. Renal involvement is observed in $60-80 \%$ of patients with SSc, while clinically based kidney symptoms in $10-40 \%$ [1, 2]. In the majority of cases, chronic renal involvement is found, which develops slowly over the years and leads to moderate renal function loss, often clinically unapparent, in $50 \%$ of the affected [2]. Apart from chronic kidney disease (CKD) with slow deterioration of the glo- merular filtration rate (GFR), the other forms of kidney involvement in SSc are: scleroderma renal crisis (SRC), which affects about $10 \%$ of SSc patients, normotensive $\mathrm{SRC}$, microalbuminuria, proteinuria and rather rare vasculitis [3, 4]. An interesting form of renal involvement in SSc is antiphospholipid-associated nephropathy with overproduction of antiphospholipid antibodies (aPL) [4]. The aPL antibodies are directed against phospholipids and their binding proteins and are frequently found in association with different connective tissue disorders (CTDs), such as systemic lupus erythematosus (SLE), rheumatoid arthritis (RA), mixed connective tissue disease (MCTD) or SSc. Connective tissue disorders with aPL antibodies may cause a diagnostic dilemma as many manifestations, e.g. hemolytic anemia, thrombocytopenia, neurologic manifes-

Correspondence: Ewa Wielosz, Department of Rheumatology and Connective Tissue Diseases, Medical University of Lublin,

Jaczewskiego 8, 20-090 Lublin, Poland, e-mail: ewa.wielosz@wp.pl

Submitted: 31.01.2016; Accepted: 3.06.2016 
tations, leg ulcerations, serositis, proteinuria, deterioration of GFR, may occur in both, CTDs and diseases associated with the presence aPL antibodies [5]. The prevalence of aPL antibodies in SSc ranges from 13 to $50 \%$ but antiphospholipid syndrome (APS) occurs in less than $1 \%$ of SSc patients [5-9]. Moreover, some reports describe, severe vascular complications in SSc patients, such as pulmonary arterial hypertension $(\mathrm{PAH})$, proteinuria, deterioration of kidney function occurring more frequently in aPL positive patients though none of the patients had clinical features of APS [10]. In the literature available, there are some data about the influence of aPL presence on GFR but no information about long - term influence of aPL antibodies on GFR in patients with SSc $[5,6,8]$. The aim of the study was the assessment of changes in GFR markers during the 24-months observation of a group of SSc patients with and without chronic aPL positivity.

\section{Material and methods}

We included in the study 50 (41 female [F] and 9 male [M]) SSc patients admitted to the Department of Rheumatology and Connective Tissue Diseases. Patients fulfilled the American College of Rheumatology (ACR) classification criteria of SSc [11]. They were classified according to

Table 1. Characteristics of the study group

\begin{tabular}{lccc}
\hline Parameter & SSc & $\begin{array}{c}\text { Group } \\
\text { I aPL(+) }\end{array}$ & Group II aPL(-) \\
\hline $\begin{array}{l}\text { Number of } \\
\text { patients }\end{array}$ & 50 & 28 & 22 \\
\hline $\begin{array}{l}\text { dcSSc } \\
\text { lcSSc }\end{array}$ & 23 & 15 & 8 \\
\hline Age (years) & $\begin{array}{c}52.6 \pm 13.4 \\
\text { (range 19-76) }\end{array}$ & $\begin{array}{c}54.6 \pm 14.1 \\
\text { (range 19-76) }\end{array}$ & $\begin{array}{c}50.0 \pm 12,2 \\
\text { (range 20-68) }\end{array}$ \\
\hline $\begin{array}{l}\text { Duration of } \\
\text { diseases (years) }\end{array}$ & $\begin{array}{c}6.2 \pm 6.0 \\
\text { (range } 0.5-26)\end{array}$ & $\begin{array}{c}6.6 \pm 6.4 \\
\text { (range 0.5-26) }\end{array}$ & $\begin{array}{c}5.3 \pm 5.4 \\
\text { (range 0.5-23) }\end{array}$ \\
\hline Data were presented as number & & 14 \\
\end{tabular}

the criteria of Le Roy et al. [12] as having either limited (lcSSc) or diffuse (dcSSc) cutaneous subset of the disease. The characteristics of the group are listed in Table 1 . We assessed patients in day 0 and 24 months \pm 6 months after day 0 . After 24 months, we examined 27 patients -9 patients died and 14 patients lost follow up. The causes of death are presented in Table 2. Two patients from 9 had positive aPL antibodies. We could not include the patients who died in the follow up group because we did not have the serum samples of these patients after the 24-month period. Twenty-four patients $(88 \%)$ were treated persistently with angiotensin-converting-enzyme inhibitors (ACEIs). Serum samples were obtained from each patient. Serum creatinine levels $(\mathrm{S}-\mathrm{Cr}$ ), serum cystatin $\mathrm{C}$ levels and GFR were determined in all patients. S-Cr levels were determined by the enzymatic method according to ISO standards using the Olympus AU 640 analyzer. Normal values range from 0.6 to $0.9 \mathrm{mg} / \mathrm{dl}$. The serum cystatin $\mathrm{C}$ level was determined by particle-enhanced immunonephelometry with the Behring nephelometer system. Its normal values range from $0.53-0.95 \mathrm{mg} / \mathrm{l}$. GFR was estimated according to the Cockcroft-Gault equation (CG) and Modification of Diet in Renal Disease (MDRD) study equation. The formulas were as follows:

$$
\begin{aligned}
\mathrm{CG}= & \{(140-\text { age }) \times \text { body weight }(\mathrm{kg})\} / 72 \times \mathrm{S}-\mathrm{Cr}[\times 0.85 \text { in } \\
& \text { females }]\left(\mathrm{ml} / \mathrm{min} / 1.73 \mathrm{~m}^{2}\right)[13] \\
\mathrm{MDRD}= & 186 \times \mathrm{S}-\mathrm{Cr}^{-1.154} \times \mathrm{age}^{-0.203}[\times 0.742 \mathrm{in} \mathrm{females}] \\
& \left(\mathrm{ml} / \mathrm{min} / 1.73 \mathrm{~m}^{2}\right) .
\end{aligned}
$$

The stratification of CKD was based on the recommendations of K/DOQI Stages 1-5 [14]. Proteinuria was defined as higher than $0.5 \mathrm{~g}$ per 24 hours and determined using the enzymatic method. Subjects were examined for the presence of the chosen aPL antibodies: antibodies to cardiolipin (acl) in IgM and $\mathrm{IgG}$ classes and antibodies to a- $\beta 2$ glycoprotein I (a- $\beta 2 \mathrm{GPI})$ in IgM and IgG classes. Titers of acl and a- $\beta 2$ GPI antibodies were determined by commercially available enzyme linked immunosorbent assay (ELISA) kits. ACL antibodies were detected using the AUTOSTST II ACA Isotype by HYCOR whereas a- $\beta 2 \mathrm{GPI}$

Table 2. The cause of death in the study group

\begin{tabular}{ccccccc}
\hline Gender & Age & Type of SSc & $\begin{array}{c}\text { Disease duration } \\
\text { (years })\end{array}$ & Cause of death & $\begin{array}{c}\text { Presence } \\
\text { of aPL }\end{array}$ \\
\hline 1 & Male & 57 & dcSSc & 0.5 & Gastric cancer & $(-)$ \\
\hline 2 & Female & 48 & dcSSc & 6 & Sudden cardiac arrest & $(-)$ \\
\hline 3 & Female & 68 & lcSS & 14 & Pulmonary arterial hypertension & $(+)$ \\
\hline 4 & Female & 45 & dcSSc & 7 & Pulmonary insufficiency & $(-)$ \\
\hline 5 & Female & 66 & dcSSc & 4 & Sudden cardiac arrest & $(-)$ \\
\hline 6 & Female & 63 & dcSSc & 5 & Pulmonary arterial hypertension & $(-)$ \\
\hline 7 & Female & 38 & dcSSc & 8 & Pulmonary insufficiency & $(-)$ \\
\hline 8 & Male & 43 & dcSSc & 4 & Right heart insufficiency & $(-)$ \\
\hline 9 & Female & 39 & dcSSc & 5 & Suicide & $(+)$ \\
\hline
\end{tabular}


antibodies - using ELISA IgM and IgG by Euroimmun. Results were considered positive when the concentrations were higher than $15 \mathrm{MPL} \mathrm{U} / \mathrm{ml}$ or GPL U/ml IgM and/or IgG class acl antibodies, and higher than $20 \mathrm{RU} / \mathrm{ml} \mathrm{IgM}$ and/or IgG class a- $\beta 2 \mathrm{GPI}$ antibodies. APL antibodies were measured at the beginning and at the end of the study. According to the presence of significant levels of at least one of aPL antibodies, patients were divided into two groups: group I - patients with positive aPL(+) antibodies - 14 (11 F, 3 M), 9 with dcSSc and 5 with lcSSc, and group II - patients with negative aPL (-) antibodies - 13 (11 F, 2 M), 5 with dSSc and 8 with 1SSc. All calculations were performed with Statistica 10.0 PL. Because of non-Gaussian distribution of variables, data were analyzed with the following nonparametric statistical methods: $U$ Mann-Whitney test and chi-squared tests for comparisons between groups. Wilcoxon non-parametric test was used for comparison of repeated measurements. $P$ values $<0.05$ were considered significant.

\section{Results}

According to our observations, after 24-month follow up, $14(52 \%)$ from 27 patients had positive aPL antibodies. The same 14 patients had positive aPL antibodies at the beginning of the study. There were no statistically significant differences in the prevalence of decreased DLCO, ILD, $\mathrm{PAH}$, heart involvement, gastrointestinal tract involvement, prevalence of arthritis or arthralgia, myalgia and digital ulcerations between the aPL positive and the aPL negative group (Table 3). Furthermore, we did not find significant

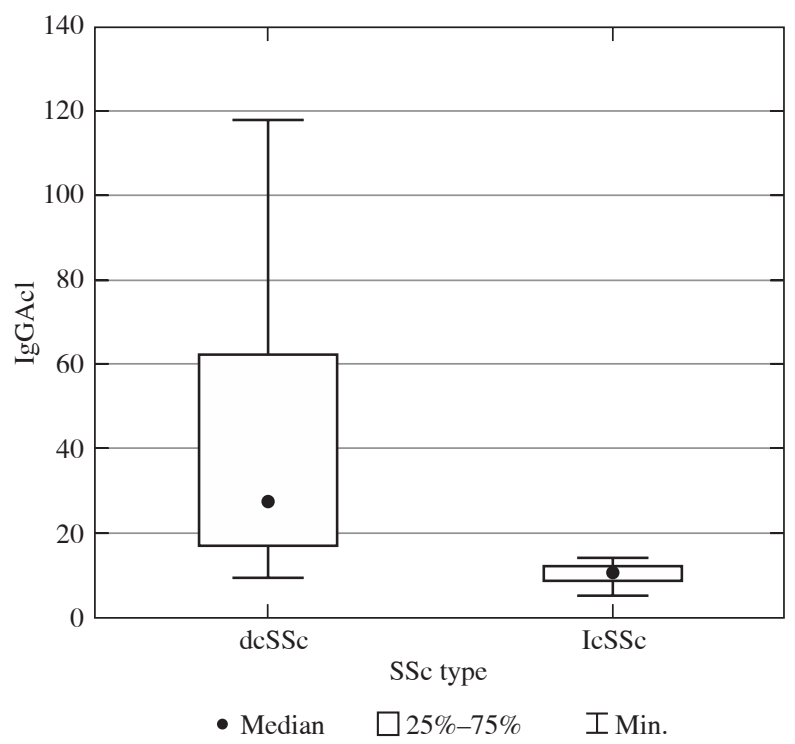

Fig. 1. Comparison of the level of cell antibodies in IgG class in the dcSSc and leSSc group differences in S-Cr levels between group I and group II before and after 24 months of observation. No statistically significant intergroup differences were found in GFR estimated by the $\mathrm{C}-\mathrm{G}$ and MDRD formulas before and after 24 months of observation. Moreover, we did not find significant differences in cystatin $\mathrm{C}$ levels before and in follow up between aPL negative and aPL positive (Mann-Whitney test) (Table 4). In follow up observations, the presence of anti-centromere antibodies (ACAs) was significantly more frequent in the aPL positive group compare to the aPL negative group (77\% vs. $0.0 \% ; \chi^{2}=5.93 ; p=0.01$ ) (Table 5). There were not significant differences in the presence of a-Scl-70 antibodies between both group. Interestingly, in follow up, the level of acl antibodies in IgG class was significantly higher in dcSSc compare to lcSSc group (dcSSc: $27.64 \mathrm{U} /$ $\mathrm{ml}$ vs. lcSSc: $10.78 \mathrm{U} / \mathrm{ml} ; p=0.02 ; U$ Mann-Whitney test) (Fig. 1). We also found that in follow up aPL positive group, the hemoglobin $(\mathrm{Hg})$ level was significantly lower in the dcSSc group compared to the lcSSc group (dcSSc: 11.6 g/dl v. lcSSc: $13.6 \mathrm{~g} / \mathrm{dl} ; p=0.03$; U Mann-Whitney test) (Fig. 2). We showed that in follow up aPL negative group, proteinuria was significantly higher in patients with dcSSc compared to $1 \mathrm{cSSc}$ patients $\left(57.1 \%\right.$ vs. $0.0 \% ; \chi^{2}=5.71 ; p=$ $0.01)$. This results refer to the percentage of patients. We did not observe history of thrombosis, emboli or miscarriage in our study group.

\section{Discussion}

The pathomechanism of kidney damage in SSc is still a matter of debate. The etiopathogenesis was presumed to

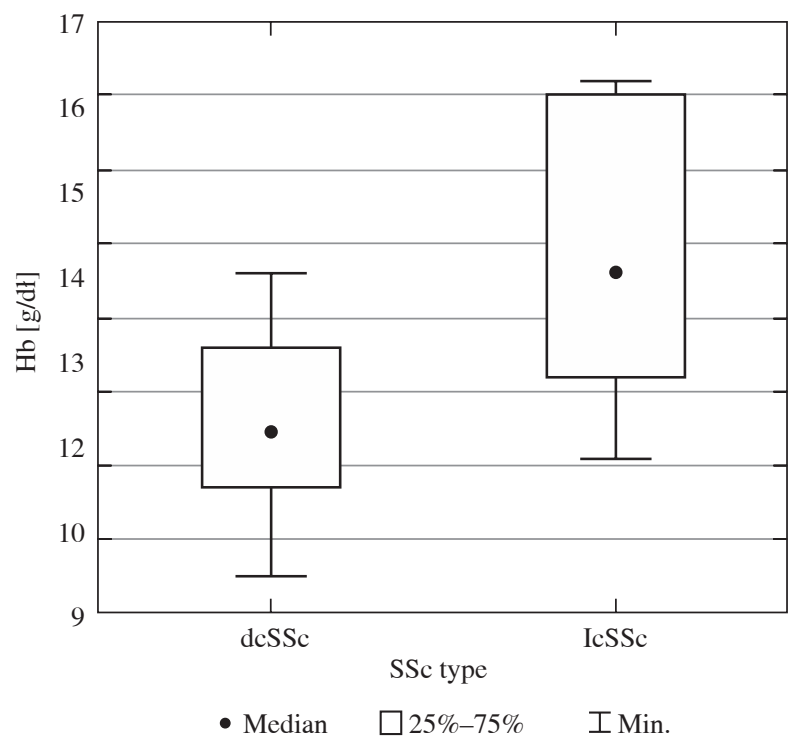

Fig. 2. Comparison of the level of hemoglobin in the dcSSc and leSSc group 
Table 3. The clinical characteristics of aPL positive and aPL negative groups

\begin{tabular}{lccc}
\hline & $\begin{array}{c}\text { aPL(+) } \\
\boldsymbol{n}=\mathbf{2 8}\end{array}$ & $\begin{array}{c}\mathbf{a P L}(-) \\
\boldsymbol{n}=\mathbf{2 2}\end{array}$ & $\begin{array}{c}\boldsymbol{p} \\
\mathbf{a P L}(+) \mathbf{v s} \\
\mathbf{a P L}(-) \mathbf{v}\end{array}$ \\
\hline ILD (HRCT) & $16(57.4 \%)$ & $13(59.1 \%)$ & 0.904 \\
\hline $\begin{array}{l}\text { Decreased } \\
\text { DLCO }\end{array}$ & $19(67.8 \%)$ & $11(50.0 \%)$ & 0.202 \\
\hline $\begin{array}{l}\text { Heart } \\
\text { involvement }\end{array}$ & $14(50.0 \%)$ & $8(36.4 \%)$ & 0.336 \\
\hline PAH (ECHO) & $9(32.14 \%)$ & $4(18.2 \%)$ & 0.265 \\
\hline Myalgia & $7(25.0 \%)$ & $5(22.7 \%)$ & 0.804 \\
\hline Myosistis & $5(17.86 \%)$ & $3(13.6 \%)$ & 0.683 \\
\hline Arthralgia & $25(89.3 \%)$ & $18(81.8 \%)$ & 0.448 \\
\hline Arthritis & $12(42.9 \%)$ & $7(31.8 \%)$ & 0.466 \\
\hline $\begin{array}{l}\text { Gastrointestinal } \\
\text { tract } \\
\text { involvement }\end{array}$ & $19(67.85 \%)$ & $19(86.4 \%)$ & 0.127 \\
\hline $\begin{array}{l}\text { Digital } \\
\text { ulcerations }\end{array}$ & $9(32.14 \%)$ & $5(22.7 \%)$ & 0.461 \\
\hline Data were presented as number and percentages & & \\
\hline
\end{tabular}

damage with slow deterioration of GFR $[4,15]$. There are different methods to estimate GFR. According to our previous study, estimation of renal function in SSc patients using the MDRD and serum cystatin $\mathrm{C}$ levels was found to be more accurate than evaluation of GFR using the C-G equation and S-Cr levels [6]. Mohamed et al. showed that calculations of GFR using the isotope method, such as the classic Gate's method with labeled iodothalamate and technicium (Tc)-99m diethylenetriamine-pantacetic acid (DTPA)_was a more reliable method compared to the C-G equation or MDRD [15]. Other methods, such as insulin clearance or Cr-EDTA clearance, used to estimate GFR, were too costly and time-consuming [15]. Moreover, renal Doppler studies or angiography should be considered in SSc patients with reduced GFR to rule out early renovascular involvement [15]. In our present study, we estimated GFR using cystatin C levels, C-G and MDRD formulas. According to our observations, there were no differences in S-Cr, cystatin C levels and in GFR estimated by the $\mathrm{C}-\mathrm{G}$ and MDRD equations before and after 24 months of observation, both in the positive as well as in the negative aPL group. According to literature, aPL antibodies

Table 4. Renal function test in $\mathrm{aPL}(+)$ and $\mathrm{aPL}(-)$ before and after 24 months

\begin{tabular}{|c|c|c|c|c|c|c|}
\hline \multirow[b]{2}{*}{ serum creatinine $\mathrm{mg} / \mathrm{dl}$} & \multicolumn{3}{|c|}{$\begin{array}{c}\text { aPL }(-) \\
n=\mathbf{1 3}(\text { Group II) } \\
\text { before after } \mathbf{2 4}( \pm \mathbf{6}) \text { months }\end{array}$} & \multicolumn{3}{|c|}{$\begin{array}{c}\text { aPL }(+) \\
n=14(\text { Group I) } \\
\text { before after } 24 \pm 6 \text { months }\end{array}$} \\
\hline & $0.88 \pm 0.16$ & $0.97 \pm 0.39$ & NS & $1.02 \pm 0.352$ & $0.96 \pm 0.289$ & NS \\
\hline cystatin $\mathrm{C} \mathrm{mg/l}$ & $1.26 \pm 0.59$ & $0.90 \pm 0.24$ & NS & $1.45 \pm 0.42$ & $1.19 \pm 0.65$ & NS \\
\hline Cockcroft-Gault ml/min & $82.93 \pm 25.03$ & $85.23 \pm 35.77$ & NS & $76.59 \pm 23.60$ & $76.37 \pm 25.92$ & NS \\
\hline MDRD GFR $\mathrm{ml} / \mathrm{min} / 1.73 \mathrm{~m} 2$ & $78.64 \pm 17.50$ & $78.82 \pm 32.66$ & NS & $71.89 \pm 24.78$ & $76.43 \pm 24.61$ & NS \\
\hline
\end{tabular}

Table 5. The presence of ACAs and a-Scl-70 antibodies in the aPL positive and aPL negative follow-up group

\begin{tabular}{lccc}
\hline $\begin{array}{c}\text { aPL }(+) \\
\boldsymbol{n}=\mathbf{1 4}\end{array}$ & $\begin{array}{c}\text { aPL }(-) \\
\boldsymbol{n}=\mathbf{1 3}\end{array}$ & $\begin{array}{c}\boldsymbol{p} \\
\text { aPL }(+) \text { vs. aPL }(-)\end{array}$ \\
\hline ACAs & $10(77.0 \%)$ & $0(0 \%)$ & 0.01 \\
\hline Scl-70 & $9(64.3 \%)$ & $6(46.1 \%)$ & 0.35 \\
\hline \multicolumn{2}{l}{ Data were presented as number and percentages }
\end{tabular}

be a series of damages to the kidneys resulting in endothelial injury, intimal proliferation, and narrowing of renal arterioles leading to decreased blood flow and hyperplasia of the juxtaglomerular apparatus [3]. Although SRC is rather rare in patients with SSc, pathological studies have demonstrated a very high incidence of renal vascular changes, at normal renal function and normal blood pressure. It is known that the GFR remains a cornerstone in evaluation of renal function in patients with SSc, especially in chronic subclinical forms in which $\mathrm{S}-\mathrm{Cr}$ and other parameters are normal. According to different studies, more than $60 \%$ of SSc patients develop subclinical renal are present in a large proportion of SSc patients who do not have clinical features or a history of APS. The aPL antibodies level were usually lower in SSc patients than in patients with clinical antiphospholipid syndrome. The particular role of aPL antibodies in clinical manifestations of SSc is still unknown [16]. In numerous studies, aPL antibodies, such as acl and a- $\beta 2$ GPI antibodies, have been implicated in arterial and venous microthromboembolism, recurrent miscarriage and endothelial injury in SSc patients, and are likely to be one of the causes of renal function deterioration in SSc. Some studies have suggested that acl antibodies and lupus anticoagulant are involved in renal thrombosis in non-APS patients. APS nephrop- 
athy has been described in SLE/non-APS patients with positive aPL antibodies; however, it could also develop in SSc/non-APS patients with positive aPL antibodies [4, 17] APS-nephropathy, characterized by vascular involvement associated with hypertension, acute and/or chronic kidney failure and low-grade proteinuria [17]. Bussone at al. have demonstrated thrombotic microangiopathy in $43 \%$ SSc patients in the course of SRC [18]. According to Morrisroe et al., the presence of aPL antibodies is associated with interstitial lung disease (ILD), pulmonary arterial hypertension (PAH), Raynaud's phenomenon and digital ulcers [19] and suggests that endothelial abnormalities and small vessel thrombosis may be important in the pathogenesis of these SSc features [19]. On the other hand, there are some data, which do not find significant differences in clinical manifestations of SSc between the aPL positive and aPL negative group [8]. However, in the majority of papers, mean serum levels of aPL were below the cut-off values required for the diagnosis of APS, and the issue whether low titre aPL are pathogenic or not in SSc patients is open to debate $[6,10,19]$. According to Ames, these SSc/aPL studies imply that under appropriate oxidative conditions low titre aPL may worsen some vascular clinical manifestations through enhanced lipid peroxidation and enothelin 1 production [10]. In our previous study, the presence of acl and a- $\beta 2$ GPI antibodies in IgG class was found correlated with deterioration of renal function in SSc patients. Subjects with relevantly higher levels of IgG acl antibodies had significantly higher levels of S-Cr, serum cystatin $\mathrm{C}$ and decreased GFR estimated by the $\mathrm{C}-\mathrm{G}$ and MDRD formula. Furthermore, prevalence of proteinuria was significantly higher in patients with dcSSc compared to lcSSc patients, both in positive and negative aPL groups [6]. In the present study, in follow up observations we did not observe differences in renal function parameters between the aPL positive and aPL negative groups. Interestingly, in follow up observations the presence of ACAs was significantly more frequent in the aPL positive group. The present results are comparable to the previous data as for proteinuria, which was significantly higher in patients with dcSSc compared to lcSSc patients, in the negative aPL group. Moreover in follow up observations, the level of acl in IgG class was significantly higher in the dcSSc group, compared to the lcSSc group. To sum up, the pathomechanism of kidney damage in SSc is extremely complex and is still a matter of debate. The most probable mechanism is endothelial injury induced by angiogenetic and angiostatic factors, such as endothelin 1, vascular endothelial growth factor, thrombomodulin, which leads to vascular lesions with generalized microangiopathy and systemic fibrosis [20]. Moreover, aPL, such as acl and a- $\beta 2$ GPI antibodies, have been implicated in various adverse events, including arterial and venous microthromboembolism, endothelial injury and APS nephropathy [21]. The findings of our previous study indicate that the presence of aPL may de- teriorate renal function in SSc patients. According to our present observations, chronic positivity for aPL antibodies does not significantly decrease the GFR in patients with SSc treated with ACEIs. The available literature lacks information about long-term influence of aPL presence on GFR in patients with SSc. Our study has some limitations, e.g. a low number of patients, lost follow up. Another limitation was that 24 of $27 \mathrm{SSc}$ patients were treated with ACEIs so the statistical analysis includes 3 patients not on ACEIs chronically. A meaningful finding of our study is that SSc patients with chronic aPL positivity should be treated with ACEIs to protect their kidney function.

The authors declare no conflict of interest.

\section{References}

1. Di Franco M, Paradiso M, Riccieri V, et al. (2007): Autonomic dysfunction and microvascular damage in systemic sclerosis. Clin Rheumatol 26: 1278-1283.

2. Amin A, El-Sayed S, Taher N, Sedki M, et al. (2012): Tc-99m diethylenetriamine pentaacetic acid (DTPA) renal function reserve estimation: is it a reliable predictive tool for assessment of preclinical renal involvement in scleroderma patients? Clin Rheumatol 31: 961-966.

3. Bose N, Chiesa-Vottero A, Chatterjee S (2015): Scleroderma renal crisis. Semin Arthritis Rheum 44: 687-694.

4. Gigante A, Rosato E, Massa R, et al. (2012): Evaluation of Chronic Kidney Disease Epidemiology Collaboration equation to estimate glomerular filtration rate in scleroderma patients. Rheumatology (Oxford) 51: 1426-1431.

5. Rai R, Swetha T (2015): Association of anti-phospholipid antibodies with connective tissue diseases. Indian Dermatol Online J 6: 89-91.

6. Wielosz E, Dryglewska M, Majdan M (2009): Antiphospholipid antibodies and kidney involvement in patients with systemic sclerosis. Clin Rheumatol 28: 955-959.

7. Zandman-Goddard G, Tweezer-Zaks N, Shalev T, et al. (2007): A novel overlap syndrome: systemic sclerosis associated with antiphospholipid syndrome-a case series. Ann N Y Acad Sci 1108: 497-504.

8. Touré AO, Ly F, Sall A, et al. (2013): Antiphospholipid antibodies and systemic scleroderma. Turk J Haematol 30: 32-36.

9. Gupta R, Thabah MM, Gupta S, et al. (2009): Clinical significance of antiphospholipid antibodies in Indian scleroderma patients. Rheumatol Int 30: 277-279.

10. Ames PR (2009): Antiphospholipid antibodies in systemic sclerosis: a double oxidative hit? Clin Rheumatol 28: 881882.

11. Arslan Tas D (1980): Subcommittee for scleroderma criteria of the American Rheumatism Association Diagnostic and Therapeutic Criteria Committee. Preliminary criteria for the classification of systemic sclerosis (scleroderma). Arthritis Rheum 23: 581-590.

12. LeRoy EC, Black C, Fleishmajer R (1988): Scleroderma (systemic sclerosis): classification, subsets and pathogenesis. J Rheumatol 15: 202-204.

13. Cockroft DW, Gault MH (1976): Prediction of creatinine clearance from serum creatinine. Nephron 16: 31-41. 
14. National-Kidney-Fundation (2002): K/DOQI Clinical practice guidelines for chronic kidney disease: evaluation, classification and stratification. Am J Kidney Dis 39: S1-S266.

15. Mohamed RH, Zayed HS, Amin A (2010): Renal disease in systemic sclerosis with normal serum creatinine. Clin Rheumatol 29: 729-737.

16. Bălănescu P, Lădaru A, Bălănescu E, et al. (2015): Association of anti phosphatidyl ethanolamine antibodies and low complement levels in systemic sclerosis patients - results of a cross-sectional study. Scand J Clin Lab Invest 12: 1-6.

17. Gigante A, Gasperini ML, Cianci R, et al. (2009): Antiphospholipid antibodies and renal involvement. Am J Nephrol 30: 405-412.

18. Bussone G, Noel LH, Mouthon L (2011): Renal involvement in patients with systemic sclerosis. Nephrol Ther 7: 192-199.

19. Morrisroe KB, Stevens W, Nandurkar H, et al. (2014): The association of antiphospholipid antibodies with cardiopulmonary manifestations of systemic sclerosis. Clin Exp Rheumatol 32: 133-137.

20. Sysa-Jędrzejowska A, Zalewska A, Dziankowska-Bartkowiak B, Waszczykowska E (2004): Evaluation of serum vascular endothelial growth factor and endostatin in systemic sclerosis patients - correlation with lung and cardio-vascular system involvement. Centr Eur J Immunol 29: 15-22.

21. Milena K. Nikolova-Vlahova, Krasimir V, et al. (2015): Antiphospholipid antibodies in patients with upper-extremity deep vein thrombosis. Centr Eur J Immunol 40: 307-310. 